\title{
The Influence of Anode Inner Contour on Atmospheric DC Plasma Spraying Process
}

\author{
Kui Wen, ${ }^{1,2}$ Min Liu, ${ }^{1,2}$ Kesong Zhou, ${ }^{1,2}$ Xuezhang Liu, ${ }^{1,2}$ Renzhong Huang, Jie Mao, \\ Kun Yang, ${ }^{2}$ Xiaofeng Zhang, ${ }^{2}$ Chunming Deng, ${ }^{2}$ and Changguang Deng ${ }^{2}$ \\ ${ }^{1}$ School of Materials Science and Engineering, Central South University, Changsha 410083, China
${ }^{2}$ National Engineering Laboratory for Modern Materials Surface Engineering Technology, The Key Lab of Guangdong for
Modern Surface Engineering Technology, Guangdong Institute of New Materials, Guangzhou 510651, China \\ Correspondence should be addressed to Min Liu; liumin_gz@163.net and Kesong Zhou; kszhou2004@163.com
}

Received 5 July 2017; Accepted 7 September 2017; Published 31 October 2017

Academic Editor: Shuo Yin

Copyright (C) 2017 Kui Wen et al. This is an open access article distributed under the Creative Commons Attribution License, which permits unrestricted use, distribution, and reproduction in any medium, provided the original work is properly cited.

\begin{abstract}
In thermal plasma spraying process, anode nozzle is one of the most important components of plasma torch. Its inner contour controls the characteristics of plasma arc/jet, determining the motion and heating behaviors of the in-flight particles and hence influencing the coating quality. In this study, the effects of anode inner contour, standard cylindrical nozzle, and cone-shaped Laval nozzle with conical shape diverging exit (CSL nozzle) on the arc voltage, net power, thermal efficiency, plasma jet characteristics, in-flight particle behaviors, and coating properties have been systematically investigated under atmospheric plasma spraying conditions. The results show that the cylindrical nozzle has a higher arc voltage, net power, and thermal efficiency, as well as the higher plasma temperature and velocity at the torch exit, while the CSL nozzle has a higher measured temperature of plasma jet. The variation trends of the plasma jet characteristics for the two nozzles are comparable under various spraying parameters. The in-flight particle with smaller velocity of CSL nozzle has a higher measured temperature and melting fraction. As a result, the coating density and adhesive strength of CSL nozzle are lower than those of cylindrical nozzle, but the deposition efficiency is greatly improved.
\end{abstract}

\section{Introduction}

Thermal plasma spraying has been widely used to prepare high quality coatings, such as wear-, corrosion-, and oxidation-resistant coatings $[1,2]$ and thermal- and environmental-barrier coatings [3, 4]. Although a large number of experimental and modeling results concerning the plasma spraying process have been published [5-7], the complicated interactions of the plasma with electromagnetic, thermal, and acoustics phenomena are still not fully understood [8]. In plasma spraying, the anode nozzle is one of the key components of the plasma torch. Slight geometrical structure modification will result in a strong change in the length and stability of the plasma arc, the characteristics of plasma jet, and the thermal efficiency of plasma torch. The effects of anode nozzle on the plasma spraying process can be summarized in the following two aspects. First, the anode outer contour controls the formation and the intensity of turbulence that affects the cold ambient air entrained into the plasma jet $[9,10]$. Secondly, the anode inner contour determines the behavior of plasma arc inside the torch and the distributions of plasma jet temperature and velocity. Both factors will ultimately influence the coating quality, such as porosity and adhesive strength. In addition, compared with the anode outer contour, the inner contour plays a more important role in the plasma spraying process.

With regard to the vacuum plasma spraying (VPS), Cao et al. [11] reported that the plasma temperature gradient of Laval nozzle, consisting of a convergent part, a cylindrical channel, and a bell-shaped divergent exit (CCD-bell nozzle), was smaller than that of standard cylindrical nozzle (cylindrical nozzle), and it can improve the deposition efficiency and density of coatings. Rahmane et al. [12] proved that the length of the bell-shaped part also had a significant effect on the plasma jet characteristics. As the pressure decreased, the plasma jet of the longer CCD-bell nozzle reached the 
supersonic state, while that of the shorter one was still in the subsonic state. Certainly, only when the working parameters were set properly, the Laval nozzle could accelerate the plasma jet to supersonic and improve the plasma spraying process [13].

As for the atmospheric plasma spraying (APS), Henne et al. $[9,14]$ proved that the CCD-bell nozzles were useful for reducing the entrainment of cold ambient air and extending the axial length hot core of the plasma jet, and also the corresponding coating qualities and deposition efficiency of the Laval nozzle were improved. In addition, Schwenk et al. $[15,16]$ designed several Convergent-Divergent Laval nozzles with bell-shaped diverging exit (CD-bell nozzle). In contrast to the cylindrical nozzle, these CD-bell nozzles can gain lower arc voltage fluctuations and acoustic levels and higher thermal and deposition efficiency, while there is no significant difference in porosity and adhesive strength.

Obviously, the aforementioned investigations mainly focused on the effects of cylindrical nozzles and bell-shaped Laval nozzles on the APS process. Studies with regard to the Laval nozzle with conical shape diverging exit (CSL nozzle) were seldom reported. In our study, we have found that the deposition efficiency is improved by the CSL nozzle, but the corresponding adhesive strength is reduced. It is different from the results of the bell-shaped Laval nozzles that are reported in the previous work. The difference in those results indicated that the intrinsic relationship between the anode nozzle and the coating had not been fully revealed.

In this paper, in order to clarify the effects of anode inner contour of cylindrical nozzle and CSL nozzle on plasma spraying process under APS conditions, the plasma jet characteristics, in-flight particle motion and heating behaviors, and coating properties were systematically investigated.

\section{Experimental Details}

2.1. Plasma Torch. At present, most commercial plasma torches applied in APS use anodes with cylindrical channel, and some also use anodes with Laval-like diverging exits. Therefore, all the following experiments were performed by the F6 atmospheric plasma spraying facility (GTV GmbH, Luckenbach, Germany), which was equipped with two different inner contour anode nozzles. Figure 1(a) shows a cylindrical nozzle with an exit diameter of $6.0 \mathrm{~mm}$ and a cylindrical channel length of $20.0 \mathrm{~mm}$. The schematic of a CSL nozzle is shown in Figure 1(b), the corresponding throat and nozzle exit diameters are $7.0 \mathrm{~mm}$ and $12.5 \mathrm{~mm}$, and the axial length of the divergent part is $26.0 \mathrm{~mm}$. In addition, it is worth mentioning that the total length of the CSL nozzle is $2.0 \mathrm{~mm}$ longer than that of the cylindrical nozzle.

\subsection{Diagnostic Equipment. The enthalpy probe system} (Tekna Plasma Systems Inc., Canada) and DPVeVOLUTION system (Tecnar Automation Ltd., Canada) were used to measure the characteristics of plasma jet and in-flight particles, respectively. The plasma temperature was obtained by calculating the energy balance of the circulating cooling water in the enthalpy probe, while the Bernoulli equation was used to calculate the local velocity for low Mach number gas flow. The external and internal diameters of the enthalpy probe are $4.76 \mathrm{~mm}$ and $1.32 \mathrm{~mm}$, and the corresponding area of orifice is $1.368 \mathrm{~mm}^{2}$. The shortest measurement distance to the nozzle exit was set at $60 \mathrm{~mm}$ to avoid thermal overload of the probe tip. In-flight particle velocity, temperature, and diameter were measured by an optical sensing device DPV-eVOLUTION system. The surface temperature of the particle was measured by a high precision two-color pyrometer based on Planck's radiation law, which assumes the in-flight particles are gray body emitters with the same emissivity at both color bands. The velocity $(V)$ was calculated by multiplying the real distance $(S)$ of the slits on the photomask by the magnification factor $(K)$ of the lens and then dividing the "time of flight" $(t)$ between the two peaks of the particle signal; namely, $V=S \times K / t$. It is worth mentioning that the powder particles were radially injected into the plasma jet. More detailed theoretical information on the two measurement systems can be found in [17-20].

Figure 2 depicts the relative position of plasma torch and enthalpy probe system, while the DPV-eVOLUTION is located at the same position as the enthalpy probe system. Plasma torch was mounted on the six degrees of freedom robot to ensure the axis of the plasma torch coinciding with the axis of the enthalpy probe tip. The axial test positions ( $z$-direction) of the plasma jet can be adjusted by liner movement of the plasma torch along the axis, while the radial test positions ( $x$-direction) were controlled by the displacement controller.

2.3. Preparation of $\mathrm{Al}_{2} \mathrm{O}_{3}$ Coatings. A bulk AISI 1045 steel sheet with a dimension of $\Phi 25.4 \times 6.0 \mathrm{~mm}$ was employed as the substrate. Since aluminum oxide coatings have a wide range of industrial applications, a commercial fused $\mathrm{Al}_{2} \mathrm{O}_{3}$ powder (5-22 $\mu \mathrm{m}$, HC Stark GmbH, Germany) was selected as feedstock in the experiments, as shown in Figure 3. Argon was chosen as the carrier gas $(5 \mathrm{slpm}$, standard liter per minute), the inner diameter of the feedstock injector is $1.5 \mathrm{~mm}$, and the corresponding powder feed rate is $16.25 \mathrm{~g} / \mathrm{min}$. Other detailed spraying parameters are shown in Table 1. Note that a NiAl layer is deposited on the substrate as bonding coating prior to the deposition of $\mathrm{Al}_{2} \mathrm{O}_{3}$. Microstructures of the $\mathrm{Al}_{2} \mathrm{O}_{3}$ coatings were characterized by scanning electron microscopy (Nova NanoSEM 430, FEI, Netherlands). The adhesive strength was performed through tensile adhesion test on a universal mechanical test machine (GOPOINT Testing Equipment Co., Ltd., China) based on the ASTM C633-01 standard [21]. Three specimens for each spraying distance $(90,110$, and $130 \mathrm{~mm})$ were tested to obtain the mean adhesive strength and relative deposition efficiency (RDE). The latter is defined as the average increment of coating weight per spraying cycle, namely, the weight of $\mathrm{Al}_{2} \mathrm{O}_{3}$ coating divided by the total number of spraying cycles.

2.4. Spraying Parameters. In the actual industrial production, the adjustable spraying parameters are mainly working current, plasma gas composition, and flow rate. Therefore, it can 
TABLE 1: Spraying parameters for online measurement and $\mathrm{Al}_{2} \mathrm{O}_{3}$ coatings deposition.

\begin{tabular}{lcccc}
\hline Case & Current $(\mathrm{A})$ & $\operatorname{Ar}(\mathrm{slpm})$ & $\mathrm{H}_{2}(\mathrm{slpm})$ & Spraying distance (mm) \\
\hline I & 650 & 40 & 10 & $60-150$ \\
II & $450,550,650$ & 40 & 10 & 90 \\
III & 550 & $40,50,60,70,80$ & 10 & 90 \\
IV & 550 & $60,62,64,66,68$ & $10,8,6,4,2$ & 90 \\
V & 650 & 40 & 10 & $70,90,110$ \\
VI & 650 & 40 & 10 & $90,110,130$ \\
\hline
\end{tabular}

Note. (1) Case III, the flow rate of $\mathrm{H}_{2}$ maintains $10 \mathrm{slpm}$; (2) Case IV, the total flow rate of mixture gas is $70 \mathrm{slpm}$.

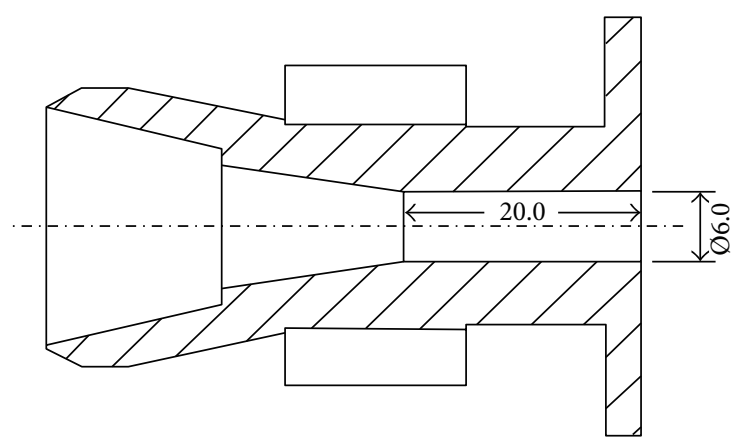

$\mathrm{mm}$

(a)

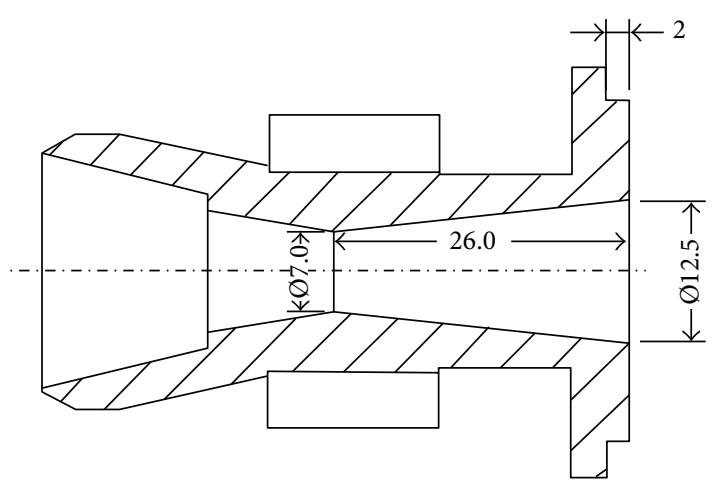

$\mathrm{mm}$

(b)

FIGURE 1: Schematic diagrams of anode nozzle inner contour: (a) cylindrical nozzle and (b) CD-conical nozzle.

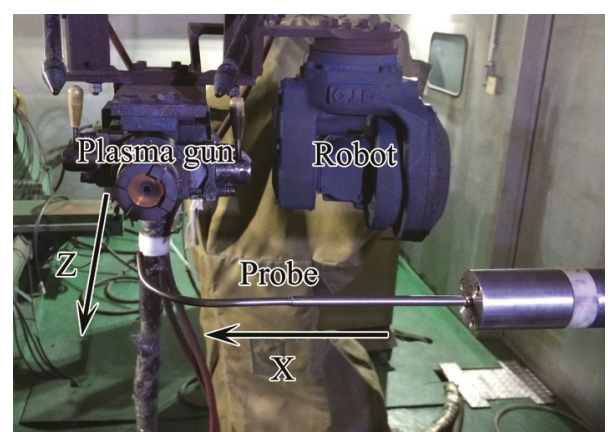

FIGURE 2: The relative position of the enthalpy probe and plasma gun.

better understand the spraying process of the two nozzles under different conditions by changing these parameters, which can provide experimental basis for the production process. The spraying parameters used in diagnostic measurement and coating fabrication are given in Table 1. Case I was used to measure the axial and radial distribution of plasma temperature and velocity. Case II, Case III, and Case IV were applied to investigate the influence of working current, argon flow rate, and hydrogen content on the plasma jet characteristics. Case V allowed measuring the in-flight particle temperature and velocity. Case VI was used to deposit the $\mathrm{Al}_{2} \mathrm{O}_{3}$ coatings.

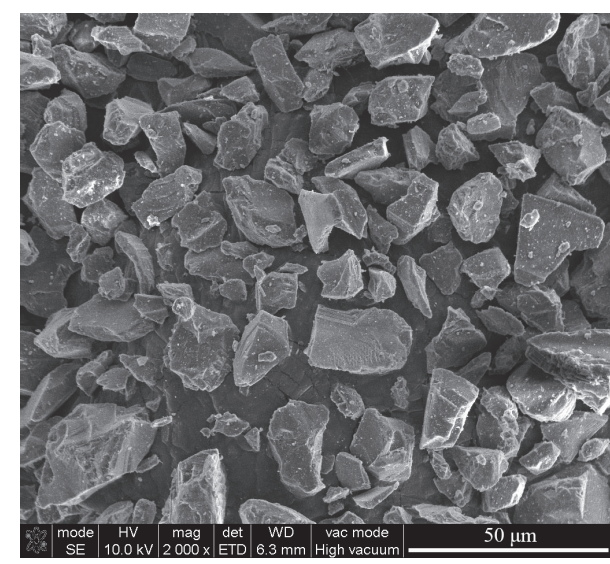

Figure 3: The morphology of fused $\mathrm{Al}_{2} \mathrm{O}_{3}$ powders.

\section{Results and Discussion}

3.1. Characteristics of Plasma Jet. Table 2 shows the voltage of the two nozzles under different working currents, as well as the corresponding net power and thermal efficiency. Here, only the case of $650 \mathrm{~A}$ is chosen to analyze the effect of the anode structure on the plasma jet characteristics, while the effect of the working current will be discussed in detail in the following parts. It can be seen from the table that, although both cylindrical and CSL nozzles operated with the same spraying parameters, the cylindrical nozzle has a slightly 
TABLE 2: Different working currents correspond to the arc voltage, net power, and thermal efficiency (Ar/ $\mathrm{H}_{2}$ : 40/10 slpm).

\begin{tabular}{|c|c|c|c|c|c|c|}
\hline \multirow{2}{*}{ Current (A) } & \multicolumn{2}{|c|}{ Voltage (V) } & \multicolumn{2}{|c|}{ Net power $(\mathrm{kW})$} & \multicolumn{2}{|c|}{ Thermal efficiency (\%) } \\
\hline & Cylindrical & Laval & Cylindrical & Laval & Cylindrical & Laval \\
\hline 450 & 75.4 & 75.3 & 18.9 & 17.6 & 55.7 & 52.0 \\
\hline 550 & 74.8 & 73.3 & 22.9 & 20.9 & 55.7 & 51.9 \\
\hline 650 & 74.3 & 72.0 & 26.0 & 23.9 & 53.8 & 51.0 \\
\hline
\end{tabular}

Note. The voltage is the average value and is obtained by reading from the console window of spraying equipment.

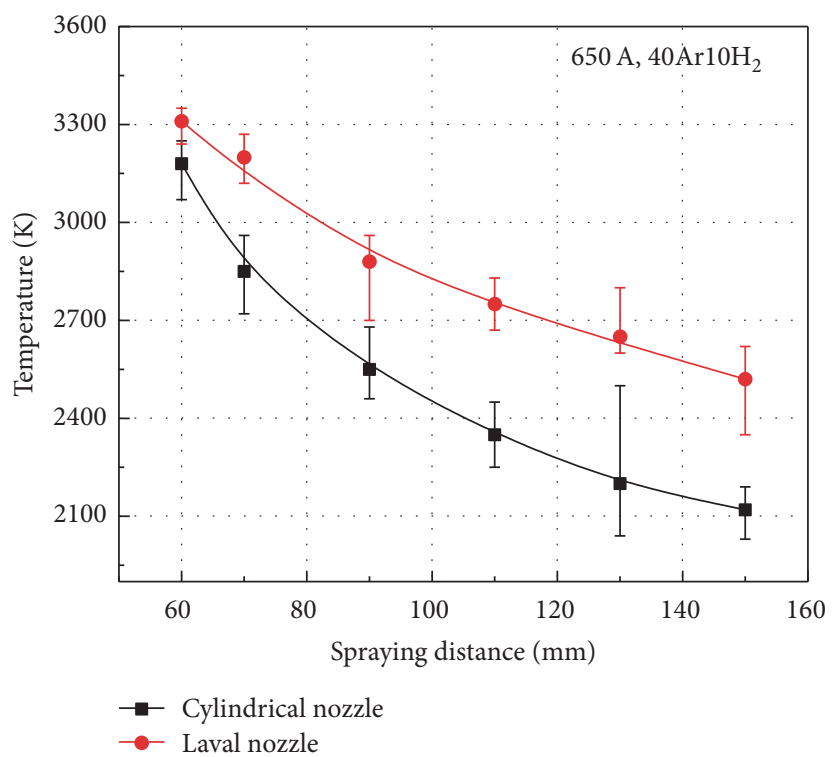

(a)

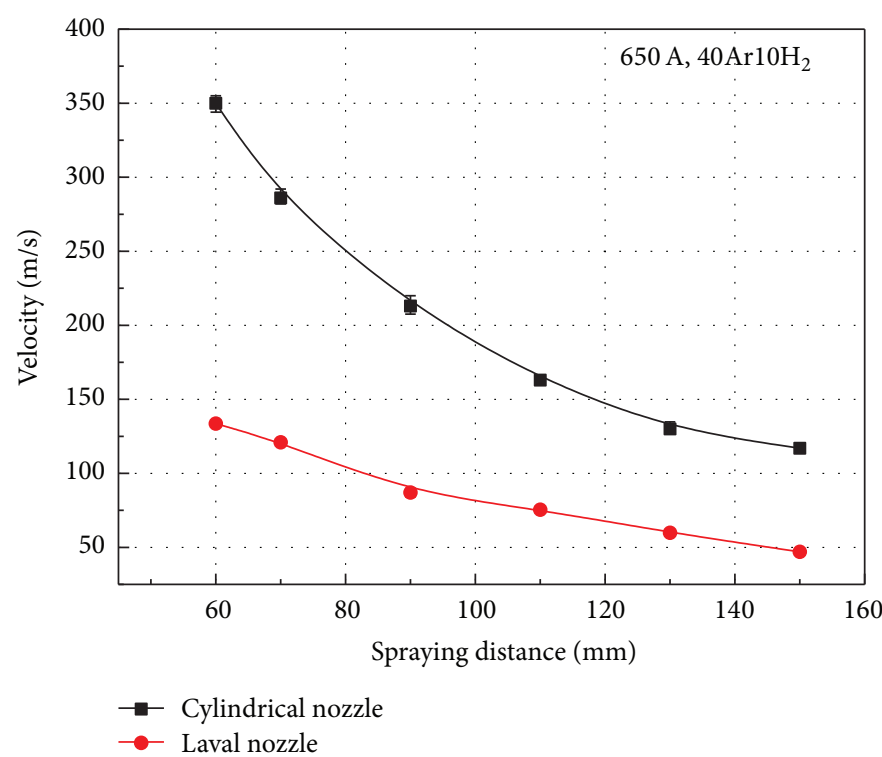

(b)

FIgURE 4: Axial profiles of measured plasma jet temperature (a) and velocity (b).

higher net power. Figure 4 presents the measured plasma temperature and velocity as functions of spraying distance. The plasma temperature of the CSL nozzle is about several hundreds of Kelvin higher than that of the cylindrical nozzle at the same measurement position. But the plasma velocity of the former is smaller within the whole measurement range, and the velocity difference became increasingly large towards the nozzle exit. Moreover, the plasma jet of CSL nozzle has a slower decrease in plasma temperature and velocity.

For the sake of convenience, we first analyze the reason for the difference in plasma velocity. Unlike the VPS, Laval nozzles typically produce subsonic plasma jets in an atmospheric environment $[16,22]$, which is consistent with what we observed in experiment. In this case, the plasma velocity at the throat of cylindrical nozzle is larger than that of CSL nozzle, because the velocity is inversely proportional to the throat cross-section area. Moreover, the velocity of the CSL nozzle in the divergent channel can be briefly illustrated by the relationship between the cross-section area and the velocity of the isentropic fluid flow, which is given as follows:

$$
\left(\mathrm{Ma}^{2}-1\right) \cdot \frac{d u}{u}=\frac{d A}{A}
$$

where $\mathrm{Ma}$ is the Mach number and $u, d u, d A$, and $A$ are the gas velocity, increment of velocity, cross-section area, and increment of the cross-section area, respectively. The Ma of subsonic flow is less than 1.0; thereby the items in the parentheses are negative. Obviously, if $d A$ is greater than zero, $d u$ must be less than zero in order to satisfy the equality condition. This fact means that the plasma flow experienced a deceleration process in the divergent part of the CSL nozzle, resulting in a smaller plasma velocity inside of the CSL nozzle.

The higher net power indicates that the plasma of cylindrical nozzle contains more energy $(E)$ which consists of internal energy $\left(c_{p} T\right)$ and kinetic energy $\left(V^{2} / 2\right)$; namely, $E=$ $c_{p} T+V^{2} / 2$. While the plasma velocity of cylindrical nozzle is much larger than that of the CSL nozzle, so it is difficult to determine which nozzle produces plasma with a higher temperature. In order to reveal the reason for the difference in temperature, a 3D numerical model was developed to compute the heat transfer and gas dynamics for two nozzles. The predicted plasma temperature distributions at the nozzle exit are shown in Figure 5, it can be seen that the temperature of cylindrical nozzle is higher. However, this is the opposite of the measurement results shown in Figure 4(a). After careful analysis, the contradictory result should be attributed to the decay rate of plasma temperature. As mentioned by Schwenk et al., the CD-bell nozzle can reduce the arc voltage fluctuations $[15,16]$ which enhanced the instability of the plasma jet and caused more cold air entrainment. 


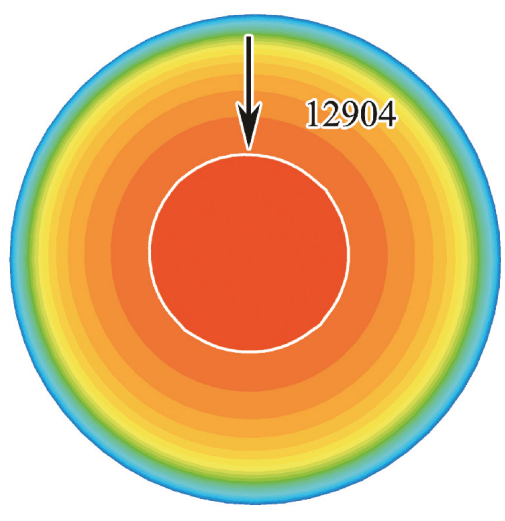

Cylindrical nozzle $(\Phi 6 \mathrm{~mm})$

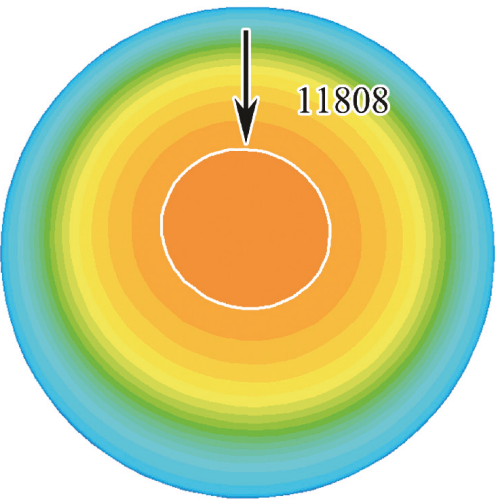

Laval nozzle (Ф $12.5 \mathrm{~mm})$

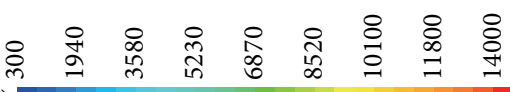

(b)

FIgURE 5: Predicted plasma temperature distributions at the exit of cylindrical nozzle (a) and CSL nozzle (b).

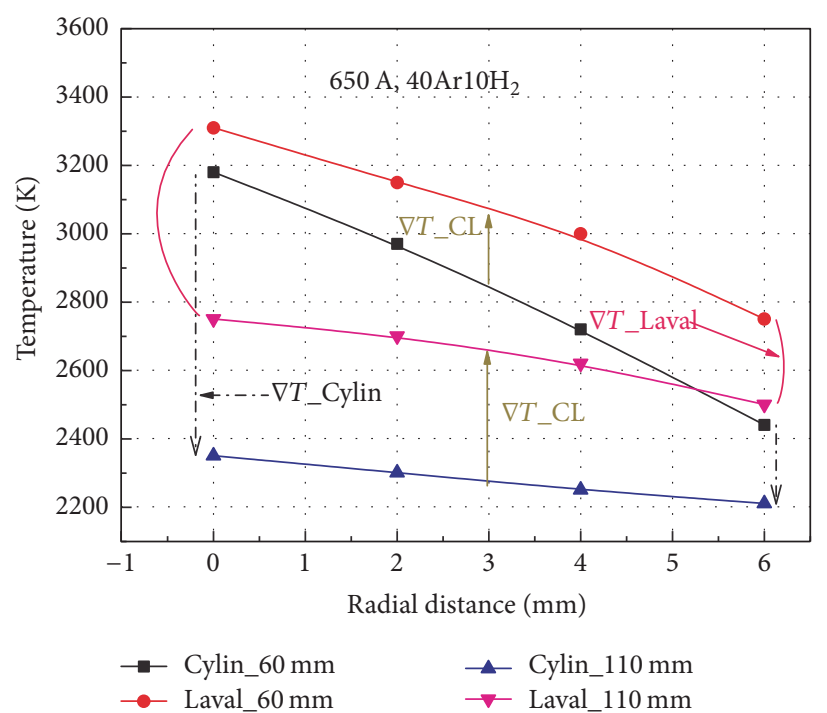

(a)

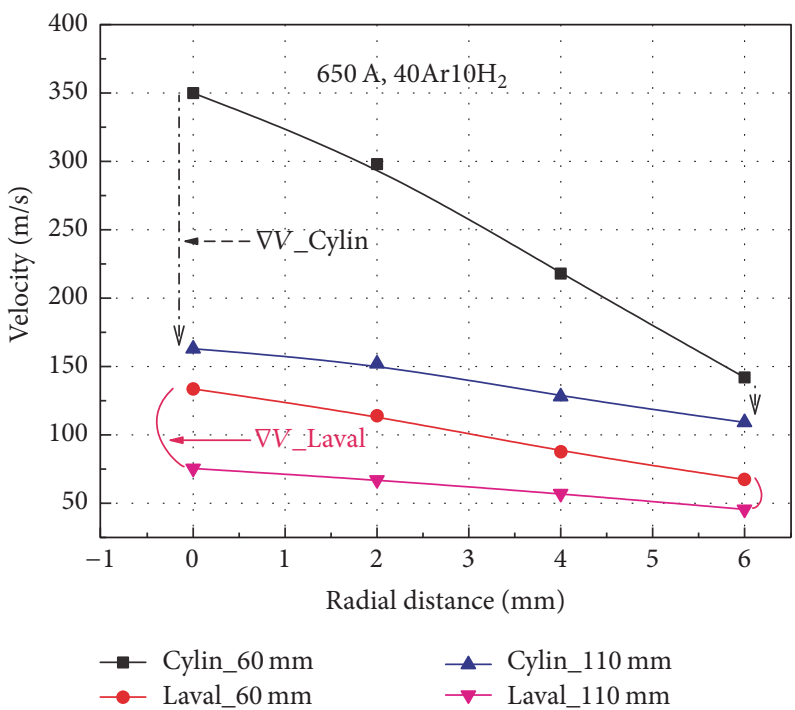

(b)

FIgURE 6: Radial profiles of measured plasma jet temperature (a) and velocity (b).

This phenomenon may also occur in the CSL nozzle with weaker arc fluctuations due to the similar inner structure. As a result, even though the plasma jet exits from cylindrical nozzle with a higher temperature, the strong ambient air entrainment caused the plasma temperature and velocity to decrease rapidly [23].

The radial distributions of plasma temperature and velocity of the two nozzles at the spraying distance of $60 \mathrm{~mm}$ and $110 \mathrm{~mm}$ are shown in Figure 6. It can be seen that the radial temperature and velocity gradients of the cylindrical nozzle jet at the $60 \mathrm{~mm}$ are larger than those of the CSL nozzle jet. These discrepancies are mainly caused by the different nozzle outlet radius that determines the size of the plasma jet. The outlet radius of the CSL nozzle is $6.25 \mathrm{~mm}$, while it is only $3.0 \mathrm{~mm}$ for the cylindrical nozzle. This fact means that the former can produce a plasma jet with larger diameter. Therefore, the measurement positions of the cylindrical nozzle probably reached the strong turbulent region of the plasma jet, but that of the CSL nozzle did not. As the spraying distance extended to $110 \mathrm{~mm}$, the interaction between the plasma jet and the cold ambient air became more significant, which reduced the radial temperature and velocity gradients. This phenomenon was more noticeable for cylindrical nozzle. In addition, at the same spraying distance, the radial temperature of the CSL nozzle jet was higher than that of the cylindrical nozzle. For example, in the case of $60 \mathrm{~mm}$ spraying distance, the plasma temperature at the radial position of $6.0 \mathrm{~mm}$ of the CSL nozzle was about 


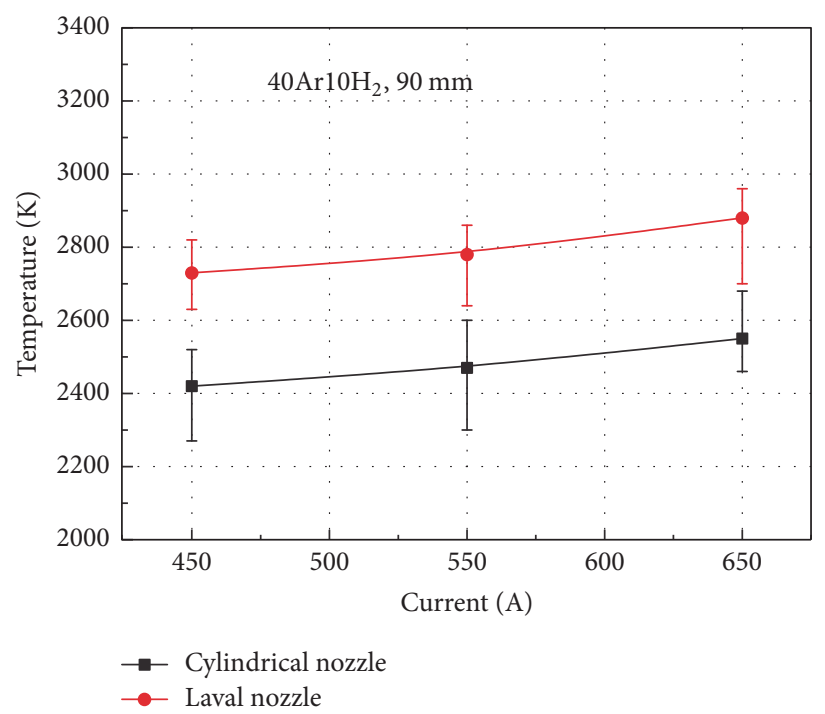

(a)

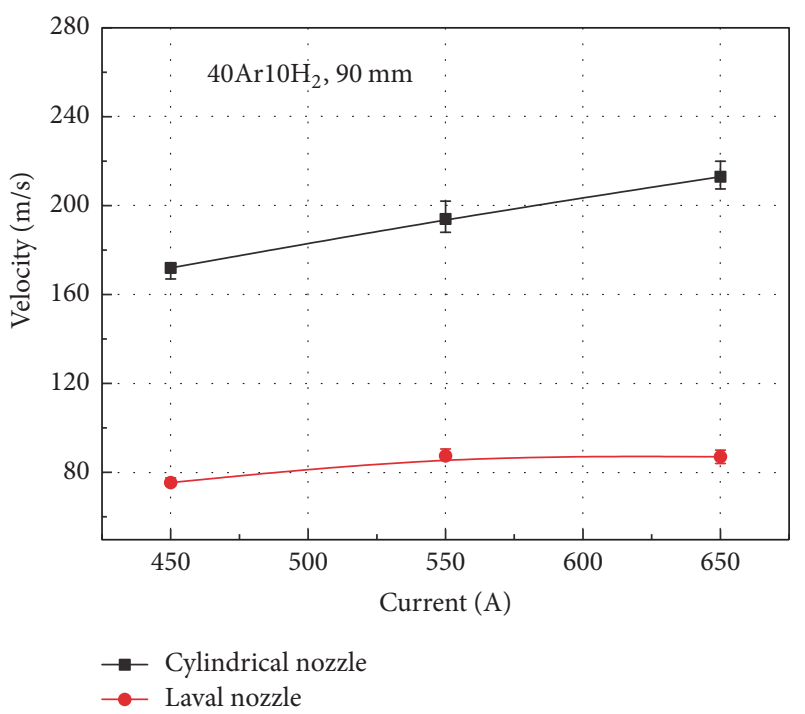

(b)

FIGURE 7: The distribution of plasma temperature (a) and velocity (b) at the different working current conditions.

$2750.0 \mathrm{~K}$, which was nearly equal to the temperature at the radial distance of $4.0 \mathrm{~mm}$ of the cylindrical nozzle.

According to Figure 6, from $60 \mathrm{~mm}$ to $110 \mathrm{~mm}$ spraying distance, the changing tendencies of the temperature difference and velocity difference of the plasma jet for two nozzles are comparable. For the sake of simplicity, only plasma temperature difference will be considered here to analyze the plasma characteristics. The symbols $\nabla T$ _Cylin and $\nabla T$ LLaval represent the plasma temperature difference of cylindrical and CSL nozzle, respectively. Both of them decreased with the increase of radial distance, and the corresponding variation of $\nabla T$ _Cylin was greater in radial direction. This fact means that the temperature reduction of the CSL nozzle jet was smoother within the entire measurement range, while a larger temperature decrease occurred in the central region of the cylindrical nozzle jet. The symbol $\nabla T$ _CL denotes the temperature difference between the cylindrical nozzle and CSL nozzle for a given spraying distance. Obviously, the $\nabla T_{\text {_CL }}$ at the distance of $110 \mathrm{~mm}$ was larger than that of $60 \mathrm{~mm}$. This fact proves once again that the plasma hot core was lengthened by the CSL nozzle. Based on the discussion of Figures 4-6, it is sensible to conclude that the CSL nozzle was able to obtain a homogeneous plasma jet with larger diameter and longer hot core compared to the cylindrical nozzle.

The influence of the electric power on the characteristics of plasma jet was studied by using different working currents (i.e., 450, 550, and $650 \mathrm{~A}$ ); the corresponding arc voltage, net power, and thermal efficiency were listed in Table 2. As can be seen from this table, for both cylindrical and CSL nozzles, the increase in current results in increasing the net power but reducing the voltage and thermal efficiency; some previously published literatures have reported similar results [24, 25]. The plasma temperature and velocity dependencies on the current are shown in Figure 7. With the increase of current, the plasma temperature and velocity increase linearly, while there is a lesser velocity increase for CSL nozzle.
In general, the arc voltage in direct current nontransferred plasma torch is approximately linearly dependent on the arc length which is determined by the balance between electromagnetic force and flow drag force [26]. The increase of current implies that a greater Lorentz force acts on the anode arc column and forces the arc to move upwards to reduce the arc voltage. Moreover, the increase in current also leads to more electric power $\left(j^{2} / \sigma\right.$, where $j$ and $\sigma$ are the current density and plasma electric conductivity) dissipating into plasma gas in the form of thermal energy, allowing more plasma forming gas to take part in the heating and ionization process. Therefore, besides the gas temperature increase, the expansion effect was also enhanced by the decreased gas density. Consequently, the plasma jet exited from the nozzle with a higher velocity and extended the plasma jet in the axial direction. In addition, the cathode jet formed in front of the cathode also played a positive role in increasing plasma velocity. Equation (2) can be used to describe the relationship between the current and the maximum velocity that the cathode jet may be reached [27]:

$$
u_{\max }=\left(\frac{\mu_{0} I}{2 \pi \rho}\right)^{1 / 2},
$$

where $u_{\max }, \mu_{0}, I$, and $\rho$ are the maximum velocity of cathode jet, permeability of vacuum, working current, and plasma density, respectively. The numerator in (2) increased as the working current increased from $450 \mathrm{~A}$ to $650 \mathrm{~A}$, while the denominator was reduced due to the decrease in density. As a result, the increased $u_{\max }$ increases the velocity of the superimposed axial plasma flow.

Table 3 lists the relationship between the argon flow rate and the plasma arc voltage, net power, and thermal efficiency of the two nozzles. For given current, the values of these variables are increased with the argon flow rate. Take the arc voltage of cylindrical nozzle as an example: when the flow 
TABLE 3: The relationship between Ar flow rate and arc voltage and net power and thermal efficiency (current: $550 \mathrm{~A}$ ).

\begin{tabular}{lccccccc}
\hline \multicolumn{2}{l}{ Working gas (slpm) } & \multicolumn{2}{c}{ Voltage $(\mathrm{V})$} & \multicolumn{2}{c}{ Net power $(\mathrm{kW})$} & \multicolumn{2}{c}{ Thermal efficiency (\%) } \\
$\mathrm{Ar}$ & $\mathrm{H}_{2}$ & Cylindrical & Laval & Cylindrical & Laval & Cylindrical \\
\hline 40 & 10 & 74.8 & 73.3 & 22.9 & 20.9 & 55.7 & 51.9 \\
50 & 10 & 78.0 & 76.0 & 24.4 & 22.7 & 56.9 & 54.3 \\
60 & 10 & 79.9 & 79.5 & 25.6 & 24.8 & 58.3 & 56.7 \\
70 & 10 & 81.0 & 82.4 & 26.4 & 26.2 & 59.3 & 57.9 \\
80 & 10 & 82.5 & 85.2 & 27.3 & 28.3 & 60.2 \\
\hline
\end{tabular}

Note. $\mathrm{H}_{2}$ flow rate is 10 slpm.

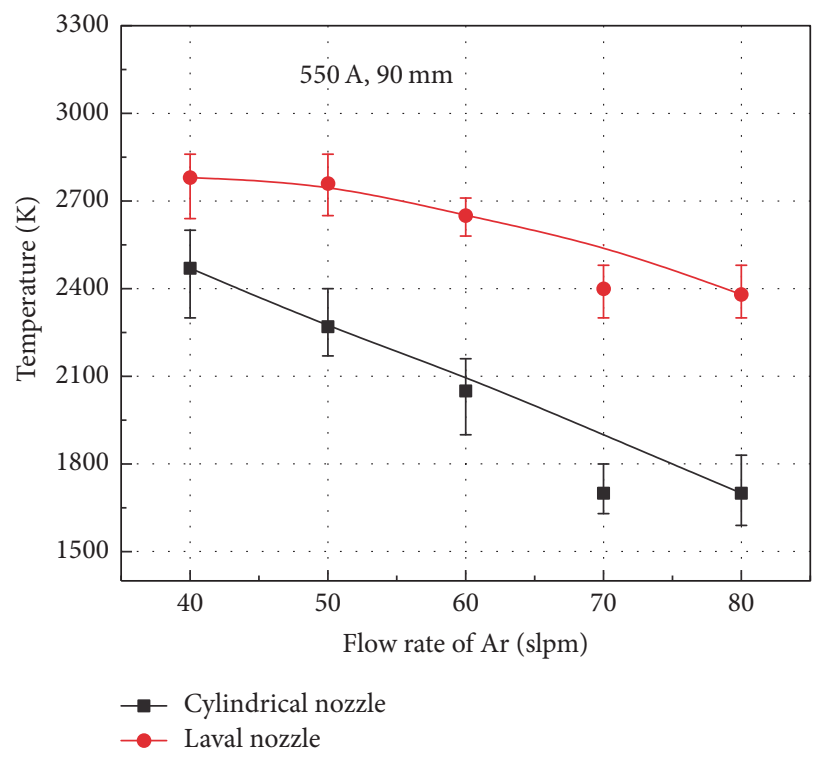

(a)

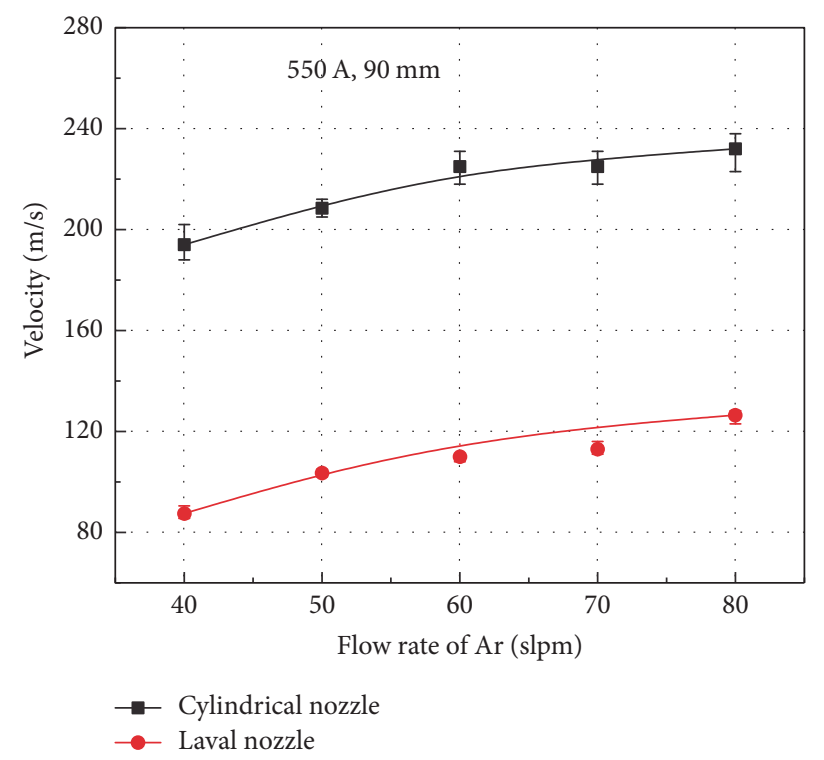

(b)

Figure 8: The profiles of plasma jet temperature (a) and velocity (b) with different Ar flow rate (flow rate of $\mathrm{H}_{2}: 10$ slpm).

rate of argon increased from 40 to 80 slpm, the corresponding arc voltage increased from 74.8 to $82.5 \mathrm{~V}$. Because the rise of the total gas flow rate increased the drag force that pushes the plasma arc to move downstream, this fact can also be qualitatively described by the following relation [28]:

$$
L_{\text {arc }} \sim \frac{\rho^{5 / 4} U_{\text {gas }}}{I},
$$

where $L_{\text {arc }}$ and $U_{\text {gas }}$ are the arc length and the velocity of working gas, respectively. The increase of argon flow rate not only increased the density of mixed gas, but also increased the working gas velocity $\left(U_{\text {gas }}\right)$. Therefore, when the working current is constant, the arc length was lengthened.

As shown in Figure 8, the plasma velocity increases with the argon flow rate, but the corresponding temperature is reduced. Generally speaking, the increase in net electric power resulting from the increased argon flow rate implies that more energy dissipated into the plasma gas, which tends to increase the plasma temperature. Whereas if the electric power was kept constant, the rise of total gas flow rate resulted in the reduction of the gas temperature [29]. In this study, the decrease of the plasma temperature due to the argon flow rate increase cannot be compensated by the corresponding electric power increment. Similar to the temperature, there were also two opposite phenomena in plasma velocity. On the one hand, the decrease of temperature caused a higher gas density, which resulted in declining plasma velocity. On the other hand, if the temperature remains constant, the gas velocity has to increase to satisfy the continuity equation with the increase of argon flow rate. As a result, the effect of the second phenomenon was more pronounced under our experimental conditions, and the plasma velocity was increased.

In order to investigate the influence of hydrogen content on the characteristics of plasma jet, the total gas flow rate was kept at $70 \mathrm{slpm}$. The values of plasma arc voltage, net power, and thermal efficiency for different hydrogen content were listed in Table 4. The increase of hydrogen content results in an increase in arc voltage, net power, and thermal efficiency. Moreover, the hydrogen content had a greater influence on these variables of the CSL nozzle than that of the cylindrical nozzle. Figure 9 shows the profiles of plasma jet temperature and velocity as functions of the hydrogen content. It can be observed that the plasma temperature and velocity of the two nozzles increased with the hydrogen content. 
TABLE 4: The relationship between $\mathrm{H}_{2}$ content and arc voltage and net power and thermal efficiency (current: $550 \mathrm{~A}$ ).

\begin{tabular}{|c|c|c|c|c|c|c|c|}
\hline \multicolumn{2}{|c|}{ Working gas (slpm) } & \multicolumn{2}{|c|}{ Voltage (V) } & \multicolumn{2}{|c|}{ Net power $(\mathrm{kW})$} & \multicolumn{2}{|c|}{ Thermal efficiency (\%) } \\
\hline $\mathrm{Ar}$ & $\mathrm{H}_{2}$ & Cylindrical & Laval & Cylindrical & Laval & Cylindrical & Laval \\
\hline 68 & 2 & 67.3 & 61.6 & 21.3 & 18.2 & 57.5 & 53.6 \\
\hline 66 & 4 & 70.9 & 68.0 & 22.4 & 20.5 & 57.4 & 54.8 \\
\hline 64 & 6 & 74.6 & 72.6 & 23.9 & 22.2 & 58.2 & 55.7 \\
\hline 62 & 8 & 77.3 & 76.1 & 24.9 & 23.5 & 58.5 & 56.2 \\
\hline 60 & 10 & 79.9 & 79.5 & 25.6 & 24.8 & 58.3 & 56.7 \\
\hline
\end{tabular}

Note. Total gas flow rate is $70 \mathrm{slpm}$.

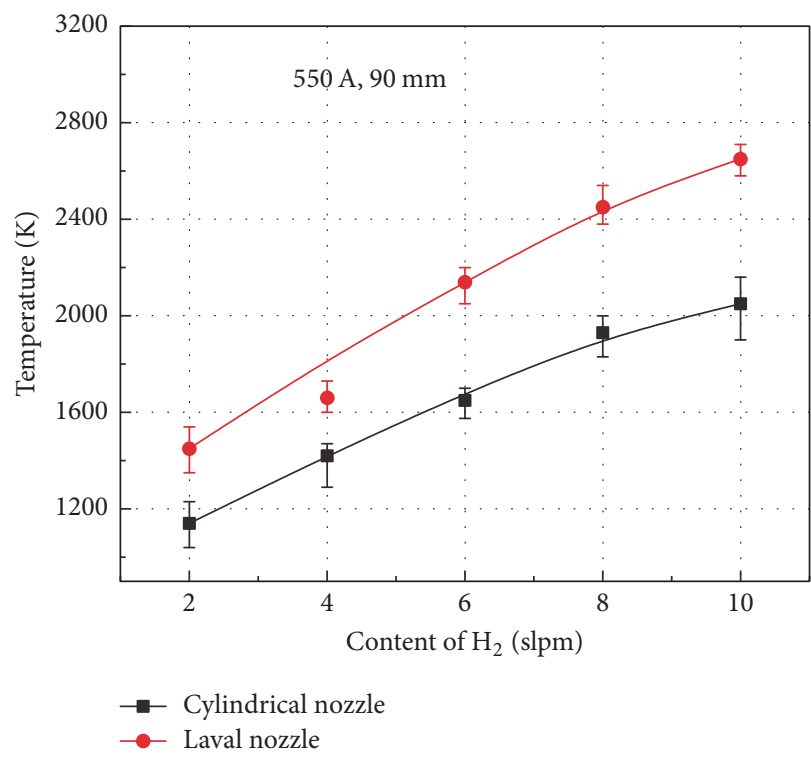

(a)

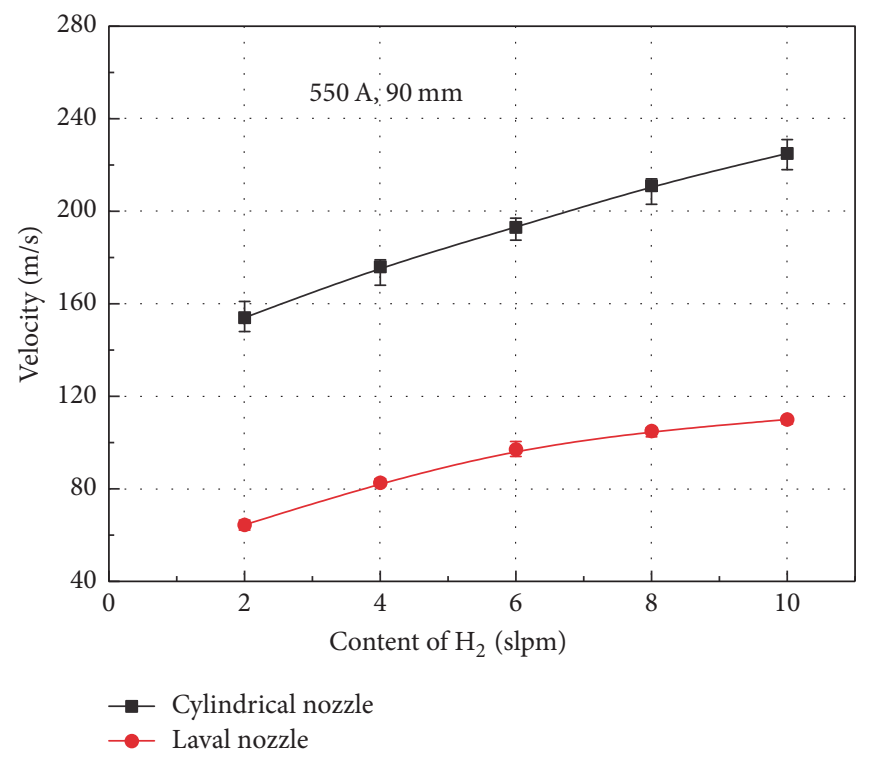

(b)

FIGURE 9: The profiles of plasma jet temperature (a) and velocity (b) with different $\mathrm{H}_{2}$ content (total gas flow rate: 70 slpm).

The hydrogen has a high specific heat and thermal conductivity, both requiring a larger electric field to sustain the plasma arc [30]. Therefore, for a given current, the arc voltage has to increase in order to provide a higher electric field strength. In other words, the increase of hydrogen content required more electric power to maintain the stability of the plasma arc, which led to the increase of the plasma temperature. As discussed in the effect of working current, the increased temperature resulting from the increased electric power leads to decreased gas density, which enhances the expansion effect of the plasma gas. In addition, the increase in hydrogen content reduces the total density of the mixed working gas, because the density of hydrogen is much lower than that of argon. Thus, the ratio in the parentheses of (2) increased with the decrease of gas density and finally increased the maximum velocity of cathode jet.

3.2. In-Flight Particle Behavior. Figure 10(a) presents the measured particle temperature decrease with the increase of the spraying distance. The temperature profile of the CSL nozzle has a greater downward trend and with a larger temperature until $90 \mathrm{~mm}$ distance. All measured temperatures are observed in the range of melting $(2,323 \mathrm{~K})$ and boiling
$(3,253 \mathrm{~K})$ point of the $\mathrm{Al}_{2} \mathrm{O}_{3}$ powder; it implies that the particle surface was in the molten state. In general, the heat transfer between the plasma jet and in-flight particle can be described by the following equation:

$$
q_{\mathrm{conv}}=\frac{\beta_{1} \beta_{2} \mathrm{Nu}_{s} \bar{k}\left(T_{\infty}-T_{w}\right)}{\left(2 r_{p}\right)},
$$

where $q_{\text {conv }}$ is the specific heat flux at the particle surface and $\beta_{1}$ and $\beta_{2}$ are the two factors used to correct the Knudsen and evaporation effects. $\mathrm{Nu}_{s}, \bar{k}, T_{\infty}, T_{w}$, and $r_{p}$ are the Nusselt number, average thermal conductivity within the Knudsen layer, plasma temperature, particle surface temperature, and particle radius, respectively. Apparently, the heat transfer occurred as long as there was a temperature difference. By comparing Figures $4(\mathrm{a})$ and 10(a), the temperature of plasma jet was higher than that of particle at the given spraying distance. According to (4), the temperature of particle should be further increased theoretically. However, the fact is that the particle temperature declined slightly. Actually, there is no contradiction here, because the particle temperature depends primarily on the ambient gas temperature of the flight trajectory. Recalling Section 2.2, the particles were fed 


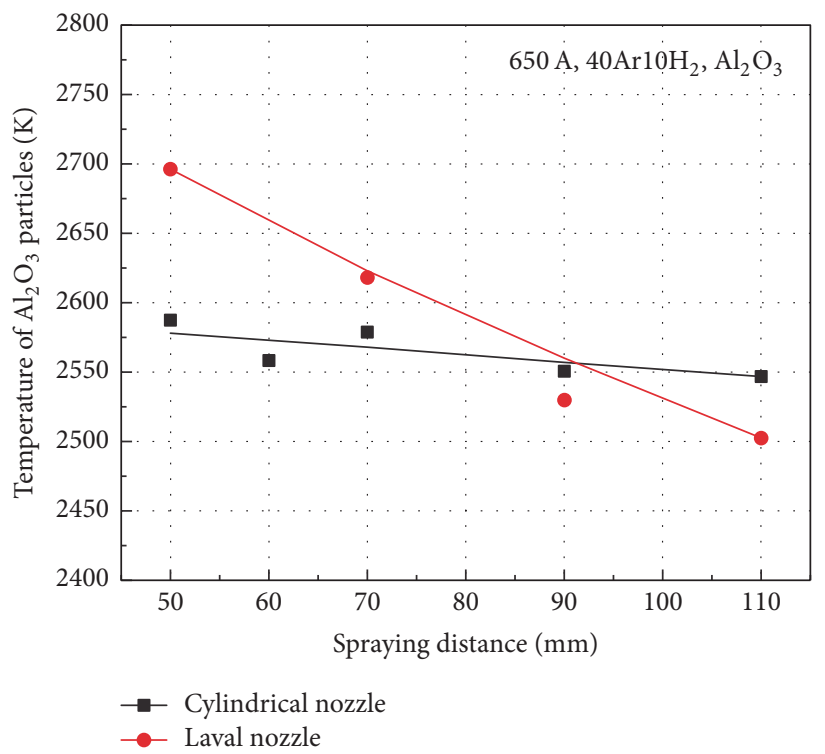

(a)

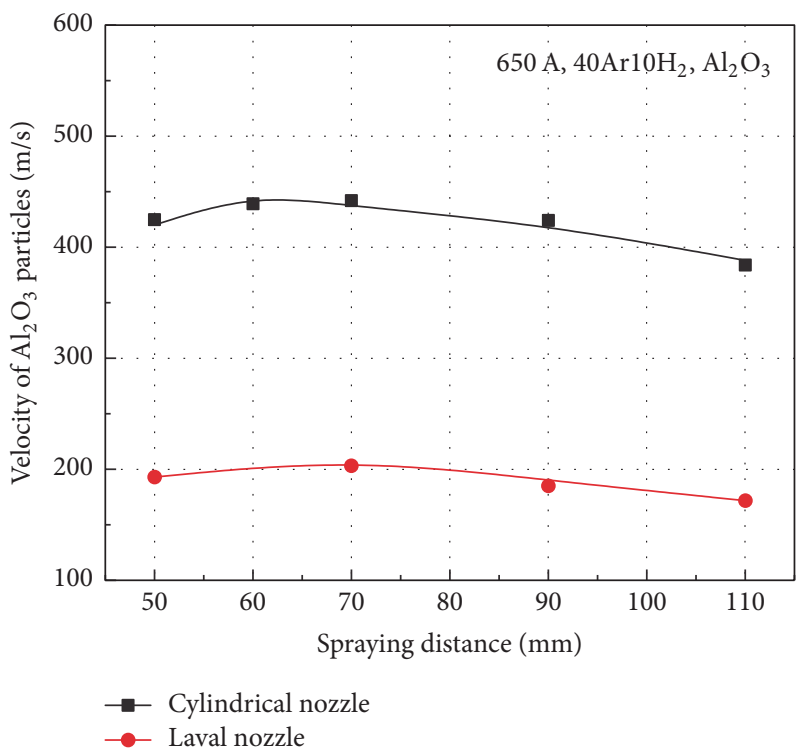

(b)

FIGURE 10: The profiles of $\mathrm{Al}_{2} \mathrm{O}_{3}$ particle surface temperature (a) and velocity (b).

along the radial direction, which means the centerline of in-flight particle jet was deviated from that of plasma jet. That is, the in-flight particle at the measured position has passed through the high temperature region; namely, $T_{\infty}-$ $T_{w}>0$. In addition, although the CSL nozzle has a lower plasma temperature at the nozzle exit, the extended plasma jet core region and the smaller plasma velocity prolong the particles residence time, which allows the injected particles to be better heated. However, the smaller velocity also extended the residence time of the particle in the cold environment, resulting in a larger decrease rate of in-flight particle along the spraying distance. Finally, the particle temperature of CSL nozzle was lower than that of cylindrical nozzle beyond $90 \mathrm{~mm}$.

The dependence of the measured particle velocity on the spraying distance of the two nozzles is shown in Figure 10(b). They show a similar behavior that the particle velocity increases first and then gradually slows down. Moreover, the particle velocity of CSL nozzle is much lower than that of cylindrical nozzle over the whole measured range. Those phenomena can be revealed by the particle motion which is mainly controlled by the fluid drag and thermophoresis forces in the plasma jet. According to Newton's second law, the force balance can be written as [31]

$$
\frac{d \vec{u}_{p}}{d t}=\frac{18 \rho C_{D}}{24 r_{p} \rho_{p}} \cdot\left|\vec{u}-\vec{u}_{P}\right| \cdot\left(\vec{u}-\vec{u}_{P}\right)+\vec{F}_{t}
$$

Here, $\vec{u}, \vec{u}_{p}$, and $\vec{F}_{t}$ are the vectors of plasma velocity, particle velocity, and thermophoresis force, respectively. The symbols $\rho_{p}, C_{D}$, and $t$ are the particle density, drag coefficient, and time. The increase in particle velocity means that the plasma jet has a larger velocity $\left(\vec{u}-\vec{u}_{P}>0\right)$, but unfortunately the plasma properties at $50 \mathrm{~mm}$ distance were not measured, because the high heat loads increase the risk of damaging the enthalpy probe. Combining the features of the plasma velocity in Figure 4(b), it can be deduced that the in-flight particles have a maximum velocity in the range of 50 to $60 \mathrm{~mm}$, and then they show a linear decrease over the whole range beyond $60 \mathrm{~mm}$ spraying distance. In addition, a larger plasma velocity of cylindrical nozzle is responsible for its larger particle velocity, because the larger relative velocity $\left(\vec{u}-\vec{u}_{P}\right)$ corresponds to a stronger acceleration process.

3.3. $\mathrm{Al}_{2} \mathrm{O}_{3}$ Coating Properties. The surface morphologies of the $\mathrm{Al}_{2} \mathrm{O}_{3}$ coatings fabricated using the cylindrical and CSL nozzles are demonstrated in Figure 11, and the spraying distance is $110 \mathrm{~mm}$. It can be observed that the coating prepared by the former has a rough surface consisting of semimolten particles, irregular splats, splashing fingers, and some open voids. However, the coating produced via the latter presents smoother surface with less semimolten particles and few splashing fingers. This fact indirectly reflects that the particles of the CSL nozzle were molten more sufficiently, which was mainly caused by the different characteristics of the plasma jet. As discussed earlier, the measured particle temperature was risen due to the extended plasma jet and the longer particle residence time; in fact, the particle melt fraction was also increased. In addition, the particle temperature of CSL nozzle was still above the melting point even though it has experienced a drastic decrease. All in all, the difference in particle temperature and melting fraction of the two nozzles is attributed to the residence time and small thermal conductivity of the $\mathrm{Al}_{2} \mathrm{O}_{3}$ powder. The later usually results in a considerable temperature gradient inside the particles, which has been confirmed by previous numerical simulation results [32]. 


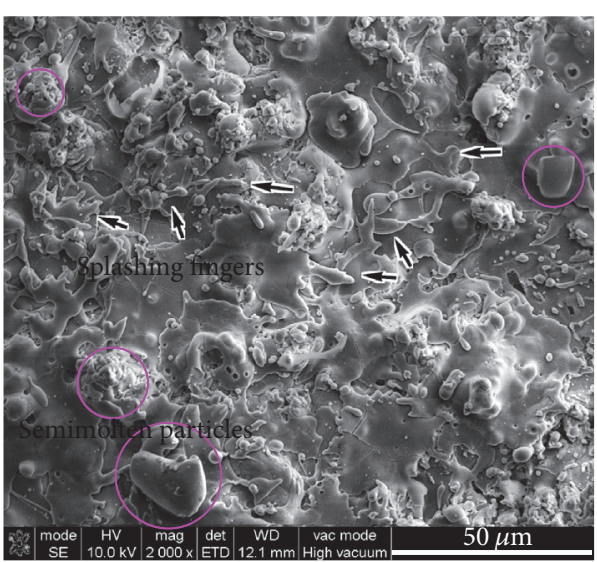

(a)

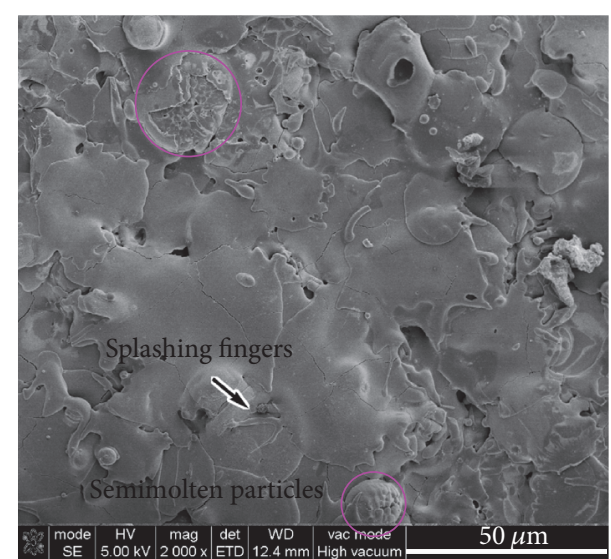

(b)

FIGURE 11: Surface micrographs of $\mathrm{Al}_{2} \mathrm{O}_{3}$ coatings prepared by cylindrical nozzle (a) and CSL nozzle (b) (current: $650 \mathrm{~A}, \mathrm{Ar} / \mathrm{H}_{2}: 40 / 10$ slpm, spraying distance: $110 \mathrm{~mm}$ ).

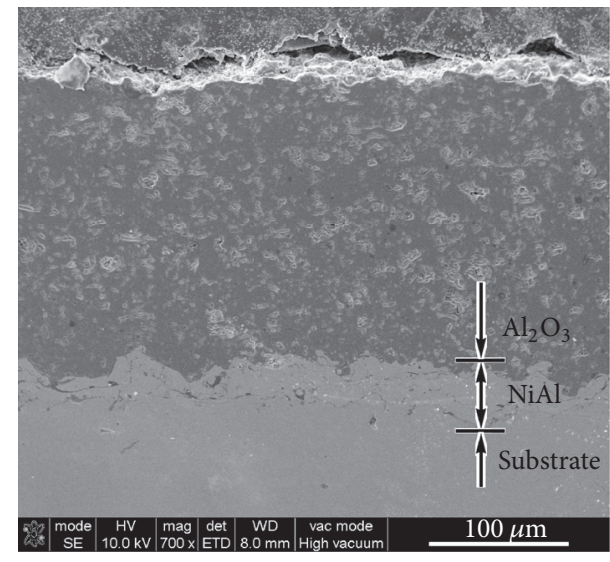

(a)

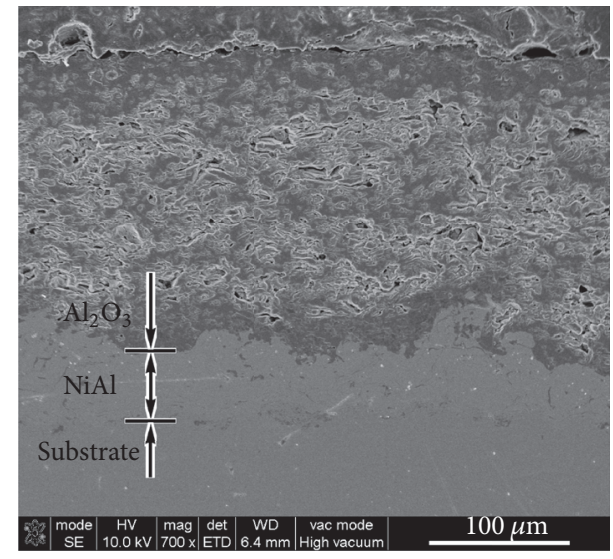

(b)

FIGURE 12: Cross-sectional SEM micrographs of $\mathrm{Al}_{2} \mathrm{O}_{3}$ coatings prepared by cylindrical nozzle (a) and CSL nozzle (b) (current: $650 \mathrm{~A}, \mathrm{Ar} / \mathrm{H}_{2}$ : 40/10 slpm, spraying distance: $110 \mathrm{~mm}$ ).

Figure 12 depicts the cross-sectional micrographs of the $\mathrm{Al}_{2} \mathrm{O}_{3}$ coatings. A dense coating was obtained by the cylindrical nozzle, whereas the coating produced by the CSL nozzle had a large number of pores, and the contact between the coating splats was not very good. Figure 13 shows the adhesive strength and the RDE of the coatings produced by the two nozzles at different spraying distances. Two phenomena can be observed in Figure 13(a): one is that the adhesive strength decreased with the increase of the spraying distance, and the other one is that the adhesive strength of the coating produced via the cylindrical nozzle was almost twice higher than via CSL nozzle. Figure 13(b) presents the average incremental weight of the $\mathrm{Al}_{2} \mathrm{O}_{3}$ coatings per spraying cycle. It is clear that the CSL nozzle has a higher $\mathrm{RDE}$ in the preparation of the coating.

By overall considering the particle velocity, melting state, and coating properties, it can be found that the effect of the particle velocity on the coating adhesive strength and porosity was greater than that on the melting state under the present experimental conditions. Even though the coating prepared by the cylindrical nozzle contained more semimolten particles, the higher velocity means that the inflight particle impacted on the substrate or as-sprayed coating with a higher kinetic energy, which enhanced the compaction effect of the coating. This improved the contact between the coating lamellas and also facilitated the filling of the pores with molten particles. As discussed in Section 3.1, the plasma jet of the CSL nozzle had a larger diameter and lower velocity. In this case, more particles can stay in the high temperature core region and undergo better effective heating, which resulted in more molten particles deposited on the substrate or as-sprayed coating, thereby increasing the RDE.

The results of the coating properties in this study are somewhat different from those reported in previous investigations, which presented that the coating properties of cylindrical and bell-shaped Laval nozzles were in the same range except the deposition efficiency. This fact suggests that the coating properties are strongly related to the structure 


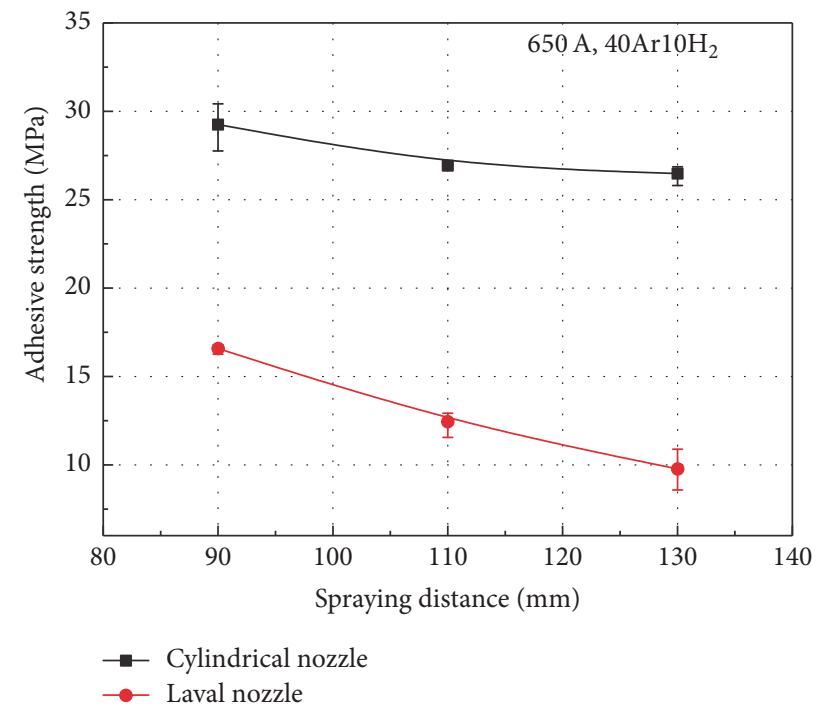

(a)

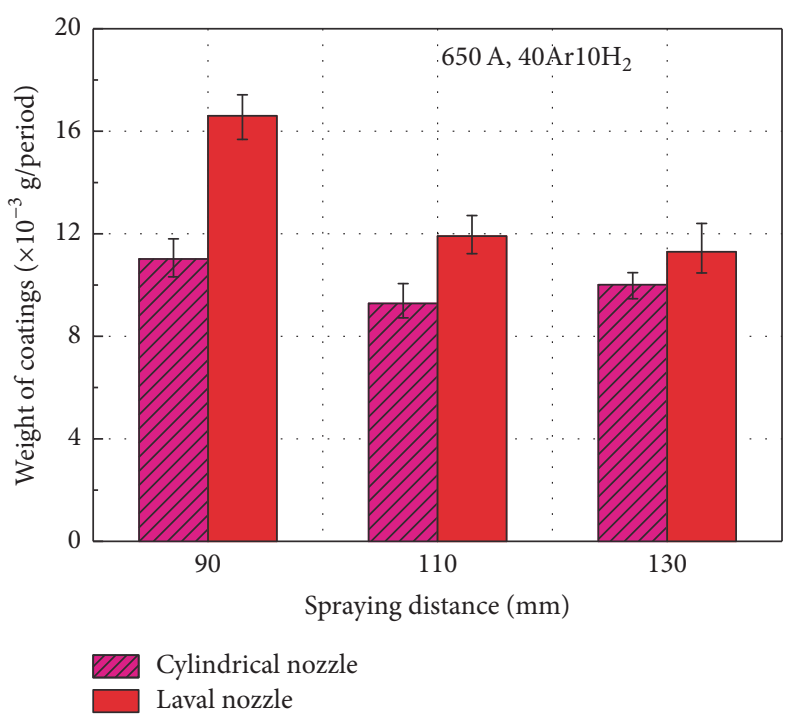

(b)

FIGURE 13: Adhesive strength (a) and average increment of coating weight per cycle (b) for different spraying distance.

of anode nozzles and the other factors such as the spraying parameters and substrate properties.

\section{Conclusions}

Thermal plasma spraying is normally regarded as a mature technology, but the detailed effect of the anode nozzle contour on the spraying process is still not fully understood. In this work, both for cylindrical and CSL nozzles, the plasma jet characteristics, in-flight particle behaviors, and coating properties have been systematically studied by experimental method, and the intrinsic relationship between them has been also revealed. The essential results obtained are as follows:

(1) For given current and plasma forming gas, the cylindrical nozzle exhibits higher arc voltage, net power, and thermal efficiency and has a higher temperature and velocity distributions at the nozzle exit. However, the plasma jet of the CSL nozzle is characterized by a higher temperature and smaller velocity with a slower downward trend in the whole measured range, which is attributed to the less entrainment of ambient cold air.

(2) Both for cylindrical and Laval nozzles, the values of arc voltage, net power, thermal efficiency, plasma temperature, and velocity are increased with the working current, Ar flow rate, and $\mathrm{H}_{2}$ content, whereas the increase in current and argon flow rate leads to a decrease of the thermal efficiency and plasma temperature, respectively.

(3) The smaller particle velocity of CSL nozzle prolongs the residence time in the high temperature region, which leads to a higher particle temperature and a larger melting fraction, but it also increases the particle residence time in the cold environment and results in a larger cooling rate. Moreover, there should be a maximum particle velocity in the range of 50-60 mm distance.

(4) In contrast to the cylindrical nozzle, the smaller particle velocity of the CSL nozzle leads to lower coating density and adhesive strength. Nevertheless, the RDE is higher because the homogeneous plasma jet has a lager diameter, which allows more particles to experience better heating.

\section{Conflicts of Interest}

The authors declare that they have no conflicts of interest.

\section{Acknowledgments}

This work was financially supported by the Guangdong Natural Science Foundation (2016A030312015), Guangdong Technical Research Program (201313050800031, 201413050502008, 2014B070706026, and 2013B061800053), and Guangdong Academy of Sciences (2017GDASCX-0843, 2016GDASPT-0206, and 2016GDASPT-0317).

\section{References}

[1] P. Fauchais, "Understanding plasma spraying," Journal of Physics D: Applied Physics, vol. 37, no. 9, pp. R86-R108, 2004.

[2] R. C. Tucker, Ed., ASM Handbook, Volume 5A: Thermal Spray Technology, ASM International, 2013.

[3] F. Chang, K. Zhou, X. Tong, L. Xu, X. Zhang, and M. Liu, "Microstructure and thermal shock resistance of the pegnail structured TBCs treated by selective laser modification," Applied Surface Science, vol. 317, pp. 598-606, 2014.

[4] X. F. Zhang, K.-S. Zhou, X. Wei, B.-Y. Chen, J.-B. Song, and M. Liu, "In situ synthesis of $\alpha$-alumina layer at top yttriumstabilized zirconia thermal barrier coatings for oxygen barrier," Ceramics International, vol. 40, no. 8, pp. 12703-12708, 2014. 
[5] G. Mariaux and A. Vardelle, "3-D time-dependent modelling of the plasma spray process. Part 1: Flow modelling," International Journal of Thermal Sciences, vol. 44, no. 4, pp. 357-366, 2005.

[6] E. Nogues, M. Vardelle, P. Fauchais, and P. Granger, "Arc voltage fluctuations: Comparison between two plasma torch types," Surface and Coatings Technology, vol. 202, no. 18, pp. 4387-4393, 2008.

[7] M. Alaya, C. Chazelas, and A. Vardelle, "Parametric Study of Plasma Torch Operation Using a MHD Model Coupling the Arc and Electrodes," Journal of Thermal Spray Technology, vol. 25, no. 1-2, pp. 36-43, 2016.

[8] A. Vardelle, C. Moreau, N. J. Themelis, and C. Chazelas, "A Perspective on Plasma Spray Technology," Plasma Chemistry and Plasma Processing, vol. 35, no. 3, pp. 491-509, 2015.

[9] R. Henne, E. Bouyer, V. Borck, and G. Schiller, "Influence of anode nozzle and external torch contour on the quality of the atmospheric DC plasma spray process, Thermal spray 2001: New surface for a new millennium," in Proceedings of the Thermal spray: New surface for a new millennium (ITSC), C. C. Berndt, K. A. Khor, and E. Lugscheider, Eds., pp. 471-478, ASM International, 2001.

[10] Y. Gao and L. T. An, "Characteristic of the arc length and voltage in a DC Bi-Anode plasma torch, Thermal spray connects: Explore its surfacing," in Proceedings of the Thermal spray connects: Explore its surfacing potential (ITSC), E. Lugscheider, Ed., ASM International, Basel, Switzerland, 2005.

[11] M. Cao, F. Gitzhofer, D. V. Gravelle, R. Henne, and M. I. Boulos, "A torch nozzle design to improve plasma spraying techniques," Plasma Sources Science and Technology, vol. 6, no. 1, pp. 39-45, 1997.

[12] M. Rahmane, G. Soucy, M. I. Boulos, and R. Henne, "Fluid Dynamic Study of Direct Current Plasma Jets for Plasma Spraying Applications," Journal of Thermal Spray Technology, vol. 7, no. 3, pp. 349-356, 1998.

[13] R. Bolot, D. Klein, and C. Coddet, "Influence of the nozzle design on the structure of a plasma jet under vacuum conditions," in Proceedings of the International thermal spray conference, E. Lugscheider, Ed., pp. 938-943, Essen, Germany, 2002.

[14] R. H. Henne, V. Borck, D. Siebold et al., "Converging-Diverging nozzles for improved atmospheric plasma spraying," in Proceedings of the $3 r$ European Congress on Thermal Plasma Processesed, pp. 247-266, 1995.

[15] A. Schwenk, G. Nutsch, and H. Gruner, "Modified nozzle for the atmospheric plasma spraying," in Proceedings of the Thermal Spray 2003 Advancing the Science and Applying the Technology, R. M. Basil and M. Christian, Eds., pp. 573-579, ASM International, 2003.

[16] A. Schwenk, H. Gruner, S. Zimmermann, K. Landes, and G. Nutsch, "Improved nozzle design of de-laval-type nozzles for the atmospheric plasma spraying," in Proceedings of the Thermal spray solution, advances in technology and application (ITSC), DVS, Osaka, Japan, 2004.

[17] G. Mauer, A. Guignard, R. Vaßen, and D. Stöver, "Process diagnostics in suspension plasma spraying," Surface and Coatings Technology, vol. 205, no. 4, pp. 961-966, 2010.

[18] G. Mauer, R. Vaen, and D. Stöver, "Plasma and particle temperature measurements in thermal spray: Approaches and applications," Journal of Thermal Spray Technology, vol. 20, no. 3, pp. 391-406, 2011.

[19] S. Yin, M. Meyer, W. Li, H. Liao, and R. Lupoi, "Gas Flow, Particle Acceleration, and Heat Transfer in Cold Spray: A review," Journal of Thermal Spray Technology, vol. 25, no. 5, pp. 874-896, 2016.

[20] M. Rahmane, G. Soucy, and M. I. Boulos, "Analysis of the enthalpy probe technique for thermal plasma diagnostics," Review of Scientific Instruments, vol. 66, no. 6, pp. 3424-3431, 1995.

[21] ASTM, "Standard test method for adhesion or cohesion strength of thermal spray coatings," 2001.

[22] R. Henne, T. Kavka, J. Arnold, and G. Schiller, "Improvement of DC thermal plasma spraying by reducing the cold gas entrainment, Thermal spray connects: Explore its surfacing," in Proceedings of the Thermal Spray Connects: Explore Its Surfacing Potential (ITSC), E. Lugscheider, Ed., Basel, Switzerland, 2005.

[23] J. R. Fincke, W. D. Swank, and D. C. Haggard, "Entrainaient and demixing in subsonic argon/helium thermal plasma jets," Journal of Thermal Spray Technology, vol. 2, no. 4, pp. 345-350, 1993.

[24] Z. Guo, S. Yin, H. Liao, and S. Gu, "Three-dimensional simulation of an argon-hydrogen DC non-transferred arc plasma torch," International Journal of Heat and Mass Transfer, vol. 80, pp. 644-652, 2015.

[25] B. Selvan, K. Ramachandran, K. P. Sreekumar, T. K. Thiyagarajan, and P. V. Ananthapadmanabhan, "Numerical and experimental studies on DC plasma spray torch," Vacuum, vol. 84, no. 4, pp. 444-452, 2009.

[26] J. P. Trelles, Finite element modeling of flow instabilities in arc plasma torches [Doctoral, thesis], University of Minnesota, 2007.

[27] S. Paik, P. C. Huang, J. Heberleinand, and E. Pfender, "Determination of the arc-root position in a DC plasma torch," Plasma Chemistry and Plasma Processing, vol. 13, no. 3, pp. 379-397, 1993.

[28] E. R. Eckert, E. Pfender, and S. A. Wutzke, "Symptomatic behavior of an electric arc with a superimposed flow," AIAA Journal, vol. 6, no. 8, pp. 1474-1482, 1968.

[29] A. Capetti and E. Pfender, "Probe measurements in argon plasma jets operated in ambient argon," Plasma Chemistry and Plasma Processing, vol. 9, no. 2, pp. 329-341, 1989.

[30] P. Fauchais, J. V. R. Heberlein, and M. I. Boulos, Thermal Spray Fundamentals. from Powder to Part, Springer, 2014.

[31] H. P. Li and X. Chen, "Three-Dimensional Modeling of the Turbulent Plasma Jet Impinging upon a Flat Plate and with Transverse Particle and Carrier-Gas Injection," Plasma Chemistry and Plasma Processing, vol. 22, no. 1, pp. 27-58, 2002.

[32] X. Chen and E. Pfender, "Unsteady heating and radiation effects of small particles in a thermal plasma," Plasma Chemistry and Plasma Processing, vol. 2, no. 3, pp. 293-316, 1982. 

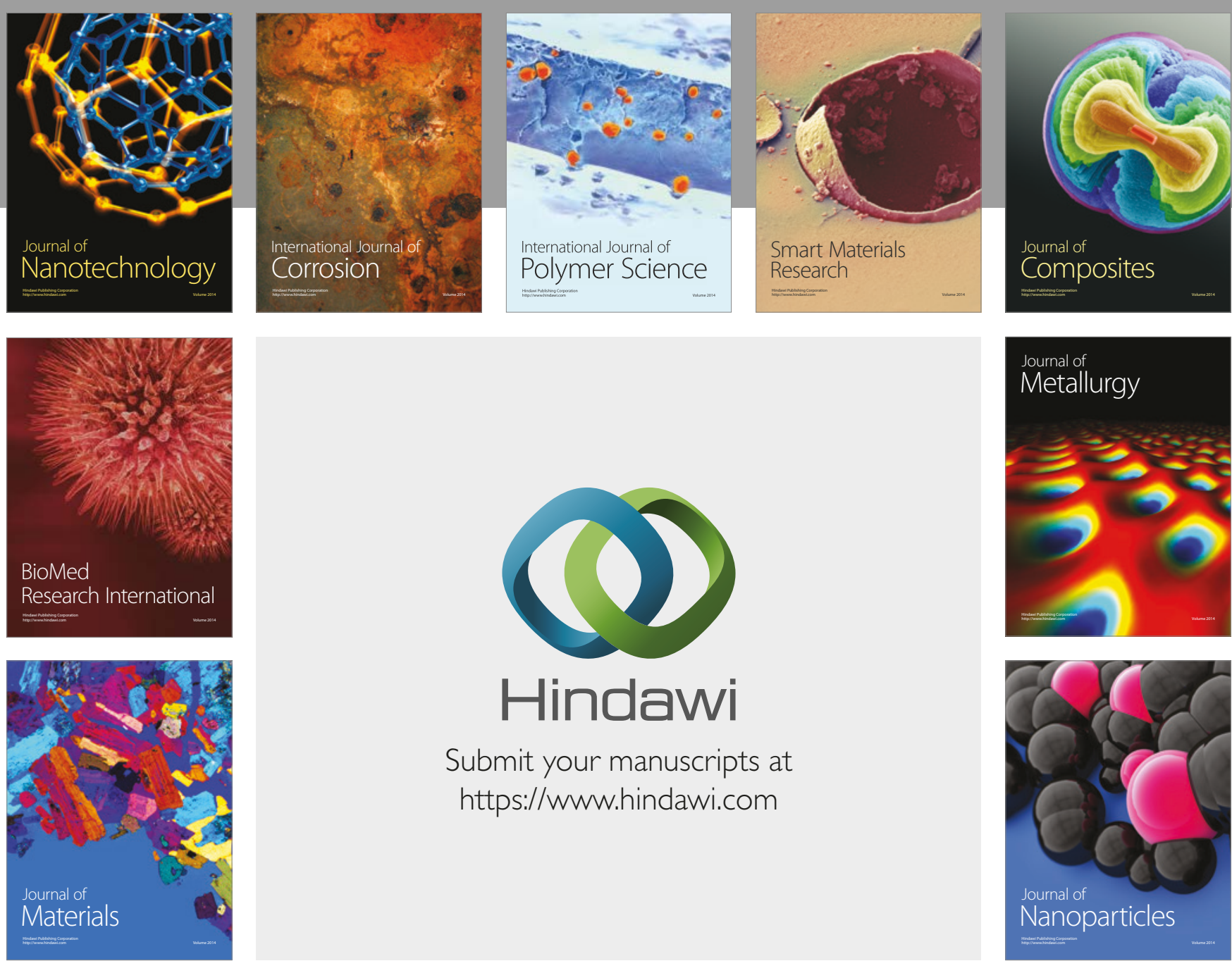

\section{Hindawi}

Submit your manuscripts at

https://www.hindawi.com
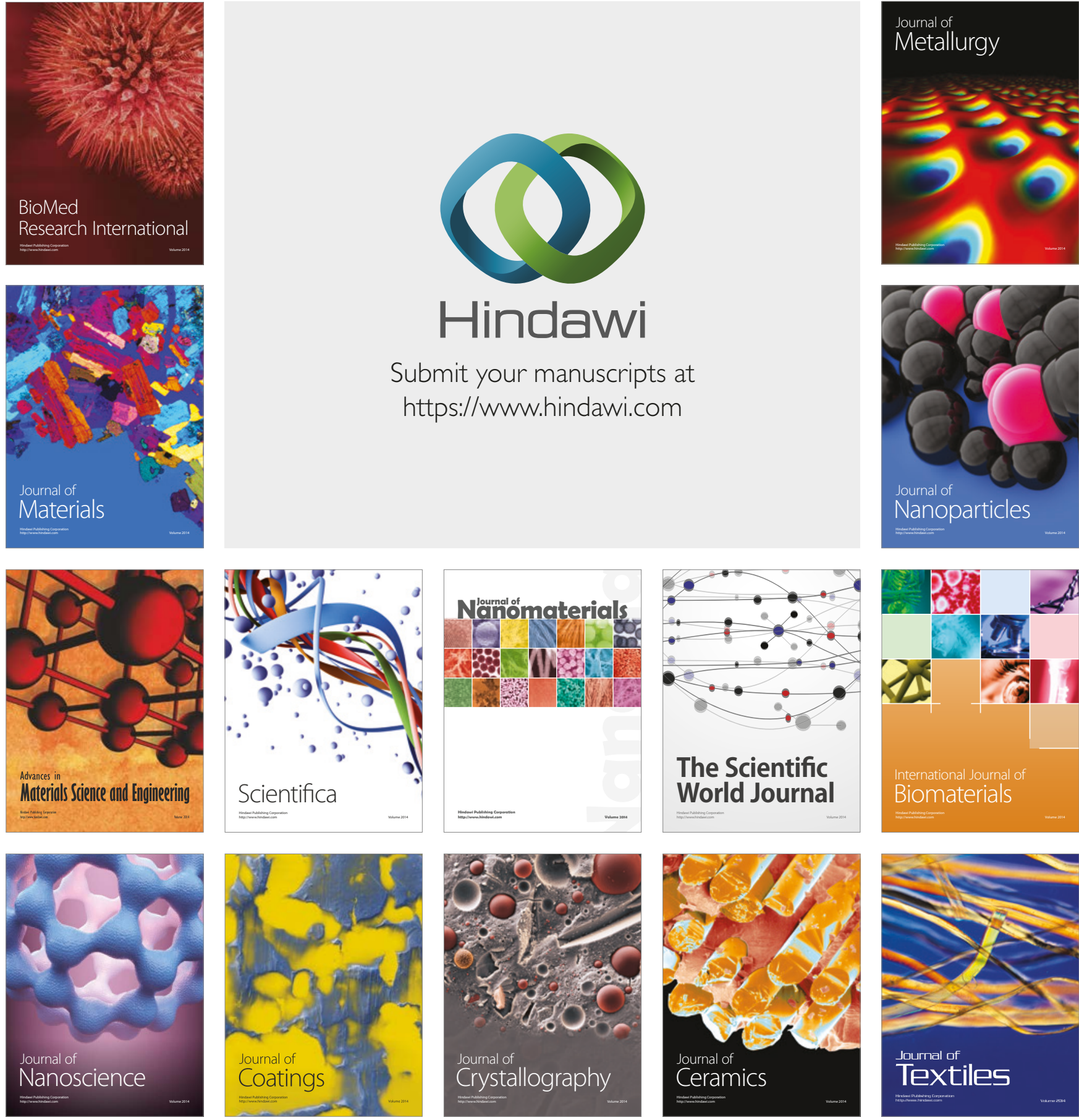

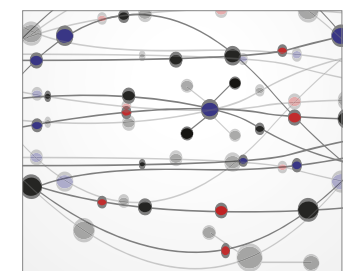

The Scientific World Journal
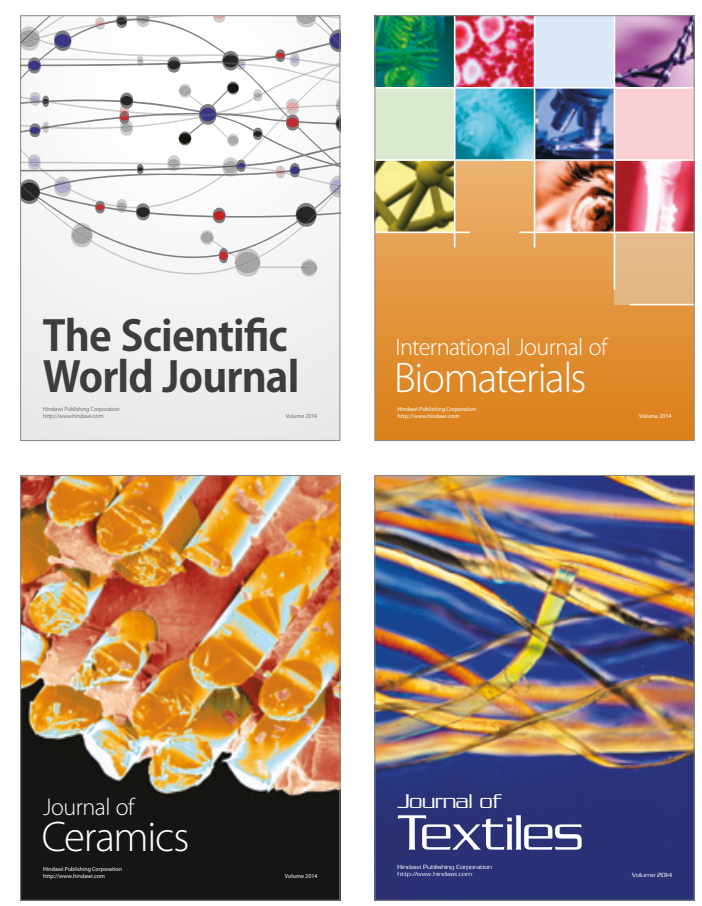